\title{
Large-scale climate and local weather drive interannual variability in Adélie penguin chick fledging mass
}

\author{
Megan A. Cimino ${ }^{1, *}$, William R. Fraser ${ }^{2}$, Donna L. Patterson-Fraser ${ }^{2}$, \\ Vincent S. Saba ${ }^{3}$, Matthew J. Oliver ${ }^{1}$ \\ ${ }^{1}$ College of Earth Ocean and Environment, University of Delaware, Lewes, DE 19958, USA \\ ${ }^{2}$ Polar Oceans Research Group, Sheridan, MT 59749, USA \\ ${ }^{3}$ Northeast Fisheries Science Center, NOAA National Marine Fisheries Service, c/o Geophysical Fluid Dynamics Laboratory, \\ Princeton University Forrestal Campus, 201 Forrestal Road, Princeton, NJ 08540, USA
}

\begin{abstract}
The fledging mass of penguin chicks can be an indicator of food availability and environmental conditions at a penguin colony. For the period 1989 to 2011, we analyzed predictor variables of environmental and food resource factors acting on multiple spatial scales near Palmer Station, Antarctica, that may influence the interannual variability in Adélie penguin chick fledging mass (CFM). To understand the influence of parental Adélie penguin diet on CFM, we modeled the energy density and krill demographics of penguin diet samples. We found a weak but significant positive relationship between the proportion of immature krill in adult penguin diets and CFM, which may indicate that krill recruitment and prey availability to adults influences CFM. However, the impact of large-scale climate and local weather outweighed the impact of parental diet characteristics on CFM. CFM was negatively associated with a positive Antarctic Oscillation (or Southern Annular Mode) and increased westerly winds and was positively associated with increased air temperature. The mechanistic relationship between climate, local weather, and CFM could include direct and indirect impacts, such as increased thermo-regulative costs for unattended chicks, decreased chick feeding frequency, and smaller meal mass for chicks driven by the geophysical transport of krill by climate and wind events.
\end{abstract}

KEY WORDS: Adélie penguin · Antarctic Oscillation · AAO $\cdot$ Chick fledging mass $\cdot$ Interannual variability

Resale or republication not permitted without written consent of the publisher

\section{INTRODUCTION}

Chicks with a high body mass at fledging have enhanced post-fledging survival and recruitment into the breeding population due to larger energy reserves that provide a buffer against energetic and environmental stresses (Naef-Daenzer et al. 2001, Morrison et al. 2009, Chapman et al. 2010, Saraux et al. 2011). Seabirds are affected by many environmental, weather, and climatic factors acting on different scales (Smith et al. 1999, Wilson et al. 2001, Ain- ley et al. 2005). The West Antarctic Peninsula (WAP) is a region of high climate variability and rapid climate change (Vaughan et al. 2003), where sea ice concentration, extent, and duration have decreased (Massom \& Stammerjohn 2010, Stammerjohn et al. 2012) and ocean temperatures have increased (Meredith \& King 2005). Primary producer and consumer abundance and community structure have been altered (Atkinson et al. 2004, Moline et al. 2004, Montes-Hugo et al. 2009), and Pygoscelis penguin populations have shown different responses to these 
changes (Ducklow et al. 2007, Forcada \& Trathan 2009). For example, Adélie penguins Pygoscelis adeliae are a circum-Antarctic, sea-ice-dependent species whose populations have declined precipitously throughout the northern WAP (Ainley 2002). The hypothesized main drivers of the trends in Adélie penguin populations and demographics include large-scale climate shifts, local weather, and food availability (Patterson et al. 2003, Forcada \& Trathan 2009, Emmerson et al. 2011, Trivelpiece et al. 2011). To gain insight into Antarctic ecosystem function in a region of rapid change, the long-term trend, and also the drivers of interannual ecosystem variability must be elucidated. Changes in climate variability are a major expected component of climate projections (Suppiah et al. 2007). Here, we aimed to understand the interannual variability in mean chick fledging mass (CFM) at a penguin colony, which is an annual integrator of large-scale climate, local weather, and food resources and represents the investment of the colony as a whole to the next generation.

Large-scale climate forcing is often associated with local atmospheric and oceanic conditions at penguinbreeding colonies. The main modes of climate variability in the Southern Ocean are the El Niño-Southern Oscillation (ENSO), which reflects oceanatmosphere interactions in the Tropical Pacific, and the Antarctic Oscillation (AAO; also known as the Southern Annular Mode), which reflects atmospheric dynamics and a meridional shift in the position and intensity of the westerly winds (Carleton 2003). Along the WAP, low sea ice conditions have been associated with warmer sea surface temperature from La Niña (Yuan 2004), and warm winds from a positive austral spring AAO (Stammerjohn et al. 2008). The ENSO has been associated with penguins breeding in the Falkland Islands (Baylis et al. 2012), Scotia Sea (Forcada et al. 2006, Trathan et al. 2006), Indian Ocean sector (Jenouvrier et al. 2005, Le Bohec et al. 2008), and Ross Sea (Wilson et al. 2001). The AAO has been related to opposing population trends between growing colonies in the Indian Ocean and Ross Sea and declining colonies along the WAP (Ainley et al. 2005). The Antarctic Dipole (ADP) is associated with the oscillation of air temperature, sea ice extent, and sea level pressure between the Pacific and Atlantic sectors (Yuan \& Martinson 2001). The ADP may be a possible driver of the interannual variability in Adélie demographics through the influence of sea ice on phytoplankton and zooplankton (Clarke et al. 2002, Fraser \& Hofmann 2003). These climate indices are hypothesized to be associated with pen- guin population dynamics, breeding success, and other life history traits through direct and indirect pathways, including food availability, prey quality, marginal ice zone, ice cover, polynya size, and terrestrial effects (Forcada \& Trathan 2009).

Nest sites offer little protection from extreme temperature, wind, and precipitation; therefore, local weather conditions at a penguin colony can impact chick growth (Chappell et al. 1990, Fraser et al. 2013). During the guard stage, adult Adélies alternate between providing protection, food, and warmth for chicks as they develop their thick, downy plumage (Bucher et al. 1990, Ainley 2002). Once plumage is developed, chicks are left unattended and gather in crèches for protection and warmth while adults simultaneously forage to meet the energetic demands of their chicks (Davis 1982, Lawless et al. 2001). Adélie chicks can cope with severe weather and maintain their body temperature within a wide range of air temperatures and wind speeds (Chappell et al. 1989). However, intense storms, blizzards, or continued exposure to precipitation can increase cold stress and thermoregulatory costs and ultimately reduce growth and survivorship (Muller-Schwarze 1984, Schreiber 2002, Patterson et al. 2003, Olmastroni et al. 2004, Demongin et al. 2010). Adélie chicks are also affected by heat stress (Murrish 1983), such as prolonged periods of temperatures $>7^{\circ} \mathrm{C}$ on sunny days with low winds (Chappell et al. 1990). Hyperthermia can create high metabolic costs due to panting and behaviors that increase the flux of heat away from the chick. Chicks can regulate their energetic consumption and metabolic demands by changing their level of activity (Salihoglu et al. 2001), but in general, chicks have few strategies to avoid weatherinduced environmental stress.

Parental care is critical to chick survivorship because parents are the sole providers of food resources and provide protection from avian predators. Prey quality, abundance, availability, and provisioning rate influence chick growth and mass (Clarke et al. 2002, Chapman et al. 2011). Adults can mediate environmental stress by providing chicks with a higher quantity and quality of prey (Chapman et al. 2011); however, this strategy is not possible when prey choices are limited. Therefore, mean CFM for a colony represents the integrated investment made by the parents to the next generation given environmental and food resource constraints. Here, we test the sensitivity of mean colony CFM to interannual variability of environmental and food resource factors acting on both large- and local-scales. We aim to understand the relative importance of parental diets 
(food quality) against the direct (temperature stress) and indirect (prey availability) effects of environmental conditions on CFM.

\section{METHODS}

\section{Adélie penguin chicks}

Prior to fledging, Adélie penguin chicks gather along 2 beaches on Humble Island $\left(64^{\circ} 46^{\prime} \mathrm{S}\right.$, $64^{\circ} 03^{\prime} \mathrm{W}$ ), which is located a few kilometers from Palmer Station, Anvers Island, Antarctica (Fig. 1). Approximately $54 \mathrm{~d}$ after hatching, the mass of a chick was recorded prior to entering the water, which is the fledging mass. We considered a fledgling to be a chick that was independent of their colony, standing on a fledging beach, and in full juvenal plumage (fully feathered, free of any downy plumage). Before weighing, all potential fledglings on the beach were censused, and we weighed $30 \%$ of the total number of fledglings. Chicks were herded together, captured with hand nets, and weighed in a bag (to the nearest $50 \mathrm{~g}$ ). Weather permitting, chicks were weighed every $2 \mathrm{~d}$ during the fledgling period, which began when the first group of chicks arrived and ended when the last chick fledged. Each chick was colormarked to avoid repeat weighing. From color-marking studies, fledglings on a fledging beach departed

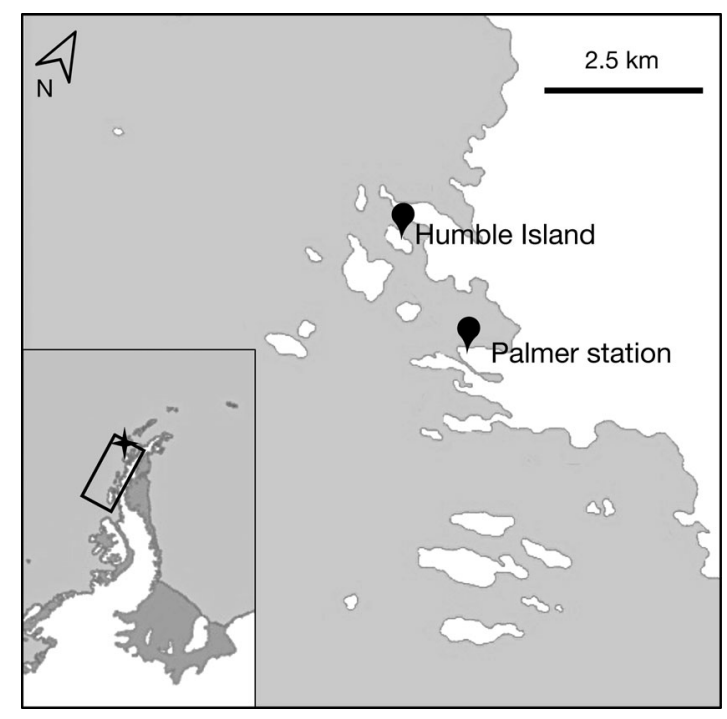

Fig. 1. The Antarctic Peninsula (inset) and the location of an Adélie penguin-breeding colony on Humble Island near the US Research Base, Palmer Station, Anvers Island. Regional sea ice observations were measured within the Palmer LTER grid (box, inset) within $\sim 2$ d. From 1987 to 2011, 90 to 400 (mean of 250) individual CFM were recorded each year. We calculated the mean CFM for each season. In our study, we could not control for clutch size or significant differences that may exist between single-chick broods and that of twins (Ainley \& Schlatter 1972, Jarvis 1974), so we focused on the interannual variability of mean CFM.

After departing from the colony, Adélie fledglings do not return to their natal breeding site until about 3 to 4 yr later (Ainley 2002). From 1987 to 2004, a fledgling resighting study on Humble Island showed that resighted birds had a significantly higher mean CFM $(3.152 \pm 0.352 \mathrm{~kg})$ compared to birds that were not resighted (3.035 $\pm 0.258 \mathrm{~kg}$; Chapman et al. 2010). Birds that were not resighted were never seen again. The chicks that were a part of the resighting study were from the same beaches as our study, making our study comparable to Chapman et al. (2010). We refer to the mass of 'resighted' and 'not resighted' birds as 'survivors' and 'non-survivors'.

\section{Environmental data}

We used large-scale climate and local weather data during the chick-rearing period (December to February) because all climate and weather events during this time have the potential to influence chick growth and mass. Climate indices may affect CFM through the remote forcing of atmospheric teleconnections on the local environment, which can directly influence chicks' terrestrial environment and change thermoregulative costs or alter marine conditions and, thus, food availability. Monthly values for the austral summer (December to February) Antarctic Oscillation (AAO), Southern Oscillation Index (SOI), and El Niño 3.4 (N3.4) were obtained from the NOAA National Weather Service, National Centers for Environmental Prediction, Climate Prediction Center (www.cpc. ncep.noaa.gov/). The AAO is the periodic strengthening and weakening of the circumpolar vortex in the Southern Hemisphere, where a strong vortex/ positive AAO is associated with stronger westerly winds around $60^{\circ} \mathrm{S}$ and warmer/wetter conditions along the WAP (Oshima \& Yamazaki 2004, van den Broeke \& van Lipzig 2004). The SOI is the difference in the air pressure anomaly between the Tahiti Islands and Darwin, Australia, and represents fluctuations in air pressure between the Western and Eastern Tropical Pacific during ENSO events. The N3.4 is the departure of sea surface temperature from the long-term mean in the Eastern Tropical Pacific at 
$5^{\circ} \mathrm{N}$ to $5^{\circ} \mathrm{S}$ and $170^{\circ}$ to $120^{\circ} \mathrm{W}$. SOI and N3.4 reflect warm El Niño (negative SOI; high N3.4) and cold La Niña (positive SOI; low N3.4) conditions in the equatorial Pacific (Kwok \& Comiso 2002, Carleton 2003). The Antarctic Dipole (ADP) is the difference between the mean ice edge anomaly at $150^{\circ} \mathrm{W}$ to $120^{\circ} \mathrm{W}$ (Pacific center) and the mean ice edge anomaly at $50^{\circ} \mathrm{W}$ to $20^{\circ} \mathrm{W}$ (Atlanic center) (Xiaojun Yuan pers. comm.), where a positive ADP signifies higher ice conditions along the WAP. Chick-rearing habitat (CRH) suitability is a spatially explicit, large-scale index from satellite-derived sea surface temperature, sea ice concentration, and bathymetry (Cimino et al. 2013), which describes the marine habitat suitability for Adélie penguins around Antarctica $(25 \times 25 \mathrm{~km}$ resolution). We used average CRH suitability within $75 \mathrm{~km}$ of Palmer Station to incorporate the Adélie's potential foraging range. For all climate indices, we created seasonal averages for the austral summer (December to February) to match with the timing of the chick-rearing period for the Adélie penguin colony on Humble Island.

\section{Local environment}

The daily local atmospheric environment around Palmer Station is influenced by air temperature, precipitation, and wind, which were measured as part of the Palmer Long-Term Ecological Research (LTER) program from 1989 to 2012 (http://oceaninformatics.ucsd.edu/datazoo/data/pallter/datasets). These atmospheric conditions can affect a chick's thermoregulative costs, and winds can alter ocean currents, water column mixing, and prey availability. Wind speeds were attenuated from $10 \mathrm{~m}$ to the height of a chick following the methods of Chapman et al. (2011), which does not account for small elevation changes at Humble Island. We calculated $u$ and $v$ wind vector components from wind speed and direction $(+u$ is a westerly wind, $+v$ is a southerly wind). We determined the number of days with high winds, cold and high temperatures, heat stress, chill factor, zero precipitation (Table S1 in Supplement 1 at www. int-res.com/articles/suppl/m513p253_supp.pdf), and mean wind chill. Daily averages were computed from hourly measurements. Seasonal averages or counts were computed for the chick-rearing period from December 19 to February 10, which corresponds to mean hatch and fledge dates (Chapman et al. 2010). The mean value does not always represent short periods (hours) of extremes or storm events (days) that affect chick growth.
Sea ice extent, duration, and day of retreat in the Palmer LTER grid (Fig. 1) was measured by the Scanning Multichannel Microwave Radiometer-Special Sensor Microwave/Imager (SMMR-SSM/I) by the National Snow and Ice Data Center and analyzed by Stammerjohn et al. (2008). From 1987 to 2011, we classified each year as having early, late, or average ice retreat by calculating the standard deviate (Quetin \& Ross 2001), where the long-term time series mean was subtracted from each annual value and then divided by the standard deviation for the long-term time series. A value less than -0.5 was considered a year of early ice retreat, $>0.5$ was late, and a value between -0.5 and 0.5 was average. We also calculated mean sea ice extent during September to November. We used sea ice classifications in our Antarctic krill Euphausia superba energetics calculations (see next section and Supplement 3 at www.int-res.com/articles/suppl/m513p253_supp. pdf) and tested the impact of ice conditions on CFM. High sea ice can act as a barrier to foraging, and alternatively, low sea ice has been associated with decreased krill availability (Atkinson et al. 2004).

The tides near Palmer Station oscillate between semidiurnal and diurnal tidal regimes. Diurnal tides aggregate krill (Bernard \& Steinberg 2013) and allow penguins to forage at shorter distances (Oliver et al. 2013). At Palmer Station, a tidal prediction model reported hourly water level predictions relative to mean sea level (Amos 1993; A. Amos pers. comm.). Following Oliver et al. (2013), we counted the number of high tides per day to determine tidal regime, where 1 high tide per day was classified as diurnal and $>1$ high tide was classified as semidiurnal. We then determined the fraction of diurnal tides during the chick-rearing period, which may be an indicator of prey availability, biomass, and, thus, Adélie foraging behavior.

\section{Converting Antarctic krill size classes into energy density and sex/maturity stages}

During our study, Adélie penguins at Humble Island almost exclusively preyed upon krill, generally $>98 \%$ krill by mass. The stomach contents of Adélie penguin adults with chicks were sampled using the lavage method (Wilson 1984). Individual krill were measured at $5 \mathrm{~mm}$ intervals from 16 to 65 $\mathrm{mm}$ to obtain size frequency distributions, but the sex was not determined. The total number and proportion of krill in each class were determined for each year during the chick-rearing period. Based on 
annual sea-ice conditions (referred to as the dynamic scenario in Supplement 3), these size class frequency distributions were then used to estimate the proportion of each sex/maturity stage and the mean wetmass energy density (WED) of krill consumed by chicks each year according to the methods of Chapman et al. (2010), which is summarized in Supplement 3 . It was necessary to convert krill size classes into sex/maturity stages and WED because krill size does not necessarily dictate energy content. Generally, during the chick-rearing period, the lipid content of immature krill is greater than that of mature males and spent females but less than that of gravid females (Chapman et al. 2010). Using this methodology, we investigated the total energy content of the annual krill cohort in parental diets and the energy content and proportion of the krill population associated with each life stage (immature krill, mature males, gravid females, and spent females).

\section{Linear and polynomial regression}

We used forward and backward stepwise regression to determine the predictor variables that were most related to CFM (MATLAB and Statistics Toolbox Release R2013a, The Mathworks, Inc., Natick, Massachusetts, USA). We used linear and quadratic models that allowed for interactions between predictor variables. The predictor variable that contributes most to a model's fit of observed data has the largest absolute value of the $t$-statistic (Kuhn \& Johnson 2013). Models in Table 1 did not have outliers, their residuals were normal, and each term in the models listed were significant at $\mathrm{p}<0.05$. Additionally, the sign of the regression coefficient of a predictor variable, interaction, or quadratic term had to be ecologically plausible and consistent between various models (Graf et al. 2005). Akaike's information criterion for small sample size $\left(\mathrm{AIC}_{\mathrm{c}}\right)$ was used to identify models that account for the most variation with the fewest terms $(k)$, select the model with the best balance between bias and precision, and avoid over fitting (Burnham \& Anderson 2002). We considered models with a $\Delta \mathrm{AIC}_{\mathrm{C}}<2$ to have substantial support and models with $\Delta \mathrm{AIC}_{\mathrm{c}}>10$ to have no support. Therefore, we only report models with a $\Delta \mathrm{AIC}_{\mathrm{C}}<10$ (Table 1 ). We also report the adjusted $\mathrm{R}^{2}$, relative likelihood, and Akaike weight.

Prior to modeling, all predictor variables were detrended if they exhibited a significant linear or quadratic trend over time $(p<0.05)$ to isolate the meaningful variability in the time series. Predictor variables that were not normally distributed were transformed to achieve normality using log or square-root transformations (Table S2 in Supplement 1). Multicollinearity, the significant correlation between predictor variables, can be problematic in regression models because information in one predictor variable is contained in its correlate. Our approach was to use predictor variables that were uncorrelated, or at least those that had a level of multicollinearity that could be ignored. To test for multicollinearity in our predictor variables before running regression models, we computed cross-correlation coefficients using Spearman's rank correlation $(\rho$; see

Table 1. Linear and linear quadratic regression models relating mean Adélie chick fledging mass (CFM) to environmental and prey quality predictor variables at Humble Island from 1989 to 2011. The model formulas are described by the number of estimated parameters $(k)$, adjusted $\mathrm{R}^{2}, \mathrm{AIC}_{\mathrm{c}}$ for small sample size, $\Delta \mathrm{AIC}_{\mathrm{c}}$ (difference from the lowest $\mathrm{AIC}$ ci amount of information lost), relative likelihood (strength of evidence), and Akaike weight representing relative model support or probabilities. The intercept is chick mass in grams. Models are sorted by ascending $\Delta \mathrm{AIC}_{\mathrm{C}}$, and only models with a $\Delta \mathrm{AIC} \mathrm{C}_{\mathrm{c}}<10$ are shown (models with a $\Delta \mathrm{AIC}_{\mathrm{c}}>10$ have little support); models with substantial support, $\Delta \mathrm{AIC}_{\mathrm{c}}<2$, in bold. Variables in the models: AAO: Antarctic Oscillation; Temp: air temperature; Uwind: $u$ wind component; WindSpeed: wind speed; NoPrecip: number of days with zero precipitation; WED: krill wet-mass energy density; Imm: proportion of immature krill

\begin{tabular}{|c|c|c|c|c|c|c|}
\hline Model formula & $k$ & $\mathrm{R}^{2}$ & $\mathrm{AIC}_{\mathrm{c}}$ & $\Delta \mathrm{AIC}_{\mathrm{c}}$ & $\begin{array}{l}\text { Relative } \\
\text { likelihood }\end{array}$ & $\begin{array}{l}\text { Akaike } \\
\text { weight }\end{array}$ \\
\hline A. $-37.46 \mathrm{AAO}+175.67 \mathrm{Temp}-113.30$ Uwind $+194.87(\mathrm{AAO} \times \mathrm{Temp})+3082.8$ & 5 & 0.60 & 260.01 & $\mathbf{0 . 0 0}$ & 1.00 & 0.35 \\
\hline B. $-59.68 \mathrm{AAO}+189.77 \mathrm{Imm}-90.78 \mathrm{Uwind}+4.30 \mathrm{NoPrecip}+2964.7$ & 5 & 0.58 & 261.18 & 1.18 & 0.56 & 0.19 \\
\hline $\begin{array}{l}\text { C. }-496.61 \mathrm{AAO}+139.07 \mathrm{WED}-112.61 \text { Uwind }+306.01 \mathrm{Temp}+91.99 \mathrm{AAO}^{2}+ \\
3626.7\end{array}$ & 6 & 0.62 & 261.59 & 1.58 & 0.45 & 0.16 \\
\hline $\begin{array}{l}\text { D. } 357.96 \mathrm{AAO}+199.66 \mathrm{Temp}-82.15 \text { Uwind }-4.23 \text { WindSpeed }-165.04(\mathrm{AAO} \times \\
\text { WindSpeed })+71.71 \mathrm{AAO}^{2}+67.50 \text { Uwind }^{2}+3065.6\end{array}$ & 8 & 0.72 & 261.61 & 1.61 & 0.45 & 0.15 \\
\hline E. $-97.84 \mathrm{AAO}-90.91 \mathrm{Uwind}+228.31 \mathrm{Temp}+61.14 \mathrm{AAO}^{2}+3060$ & 5 & 0.54 & 263.22 & 3.22 & 0.20 & 0.07 \\
\hline $\begin{array}{l}\text { F. } 468.33 \mathrm{AAO}+4.04 \text { WindSpeed }+1903.7 \mathrm{Temp}-199.79(\mathrm{AAO} \times \\
\text { WindSpeed })-611.85(\text { Temp } \times \text { WindSpeed })+77.27 \mathrm{AAO}^{2}+3031.2\end{array}$ & 7 & 0.54 & 269.15 & 9.15 & 0.01 & 0.00 \\
\hline
\end{tabular}


Fig. S1 in Supplement 2 at www.int-res.com/articles/ suppl/m513p253_supp.pdf). Because we examined a large suite of variables (Fig. S1 in Supplement 2), it was necessary to eliminate variables that were collinear and less related to CFM to reduce the possible number of regression models. Using a stringent threshold for $\rho$ of 0.5 , we eliminated correlated variables that had a less direct influence on CFM (Graf et al. 2005). The large-scale variables that were eliminated using the above criteria include the SOI, N3.4, and CRH. ADP was not included in our models because the time series only extends to 2007 . The local-scale variables that were eliminated include the number of days with high winds, number of days with cold temperatures, number of days with high temperatures, number of days with heat stress, number of days with chill factor, mean solid precipitation, and mean wind chill. Therefore, the suite of models we tested included all combinations of the AAO, $u$ and $V$ wind components, days with no precipitation, mean wind speed, mean air temperature, sea ice extent, fraction of diurnal tides, WED, and the proportion of immature krill. Subsequent to our regression models, we again tested for multicollinearity using variance inflation factors (VIFs) for predictor variables in each model (Allison 1999). VIFs provide an index to measure how much the variance of an estimated regression coefficient is increased because of collinearity in the predictors included in any given model. Multicollinearity was not a problem in our models (Table 1 ) because VIF values were $<4$ (O'Brien 2007).

\section{RESULTS}

\section{Interannual variation in CFM and krill quality}

We investigated the interannual variability in Adélie CFM from 1987 to 2011 (Fig. 2). CFM was normally distributed each year and varied from $\sim 1.5$ to $\sim 4.5 \mathrm{~kg}$. At least $25 \%$ of the CFMs were above and below the mean mass that is descriptive of surviving and non-surviving chicks each year (Chapman et al. 2010). Mean CFM varied by only $0.35 \mathrm{~kg}$ (2.835 to $3.180 \mathrm{~kg}$ ) but were generally significantly different between years that differed by $>0.05 \mathrm{~kg}$. There were 11 years with mean CFM below the mean mass of non-survivors and 5 years with mean CFM above the mean mass of survivors.

Using krill size-class frequency distributions from Adélie penguin diets from 1987 to 2011, we estimated the interannual variation in WED and the pro-

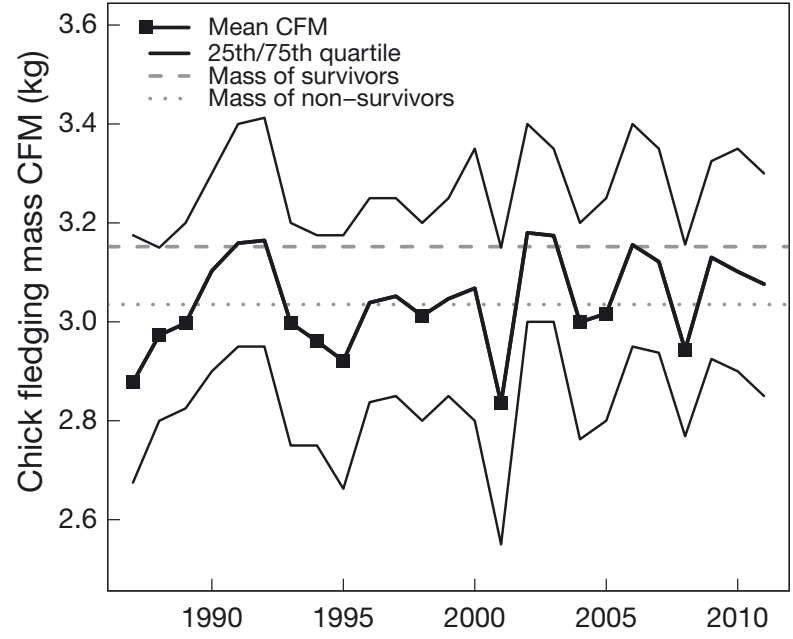

Fig. 2. Mean mass of surviving and non-surviving Adélie penguin chicks taken from a fledgling resighting study (Chapman et al. 2010). Mean CFM oscillates between the mean mass of survivors (CFM > $3.152 \mathrm{~kg}$; $)$ ) and nonsurvivors (CFM < $3.035 \mathrm{~kg}$; $\mathbf{a})$ from 1987 to 2011. O represent mean CFM values between the mean mass of survivors and non-survivors. Interannual variability in the 25th and 75th quartile of mean CFM is also shown. Years represent the austral summer field season, e.g. $1987=$ Dec 1987 and Jan and Feb 1988

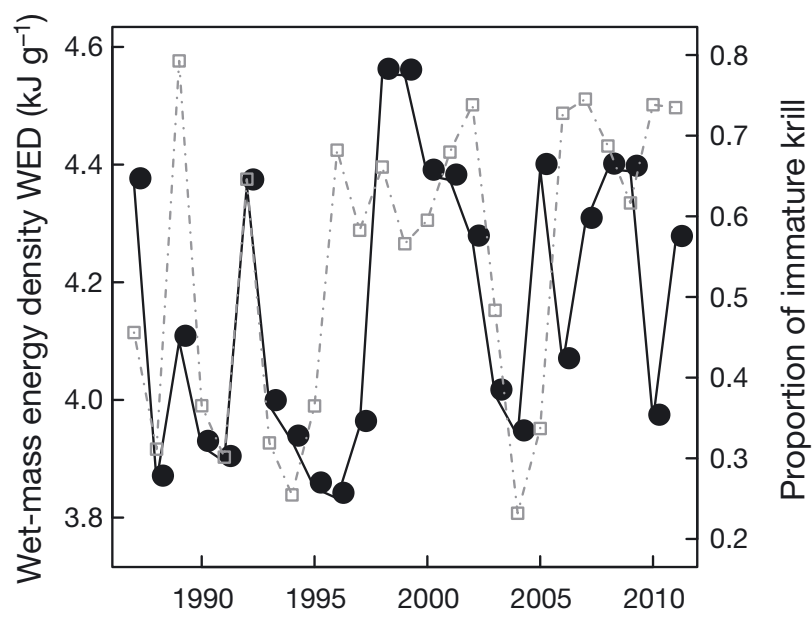

Fig. 3. Interannual variability in WED (•) and the proportion of immature krill ( $\square$ )

portion of each sex/maturity stage using the methods of Chapman et al. (2010) (Fig. 3). Estimates of WED were not correlated to CFM $(\rho<0.1)$. The range of WED was comparable to previous studies, which show WED varies from 3.5 to $5.0 \mathrm{~kJ} \mathrm{~g}^{-1}$ (Davis et al. 1989, Nagy \& Obst 1992, Janes \& Chappell 1995). CFM was not correlated to the proportion of mature males, mature females, gravid females, or larger krill in the diet, but it was moderately correlated to the proportion of immature krill $(\rho=0.33, p=0.11)$. 


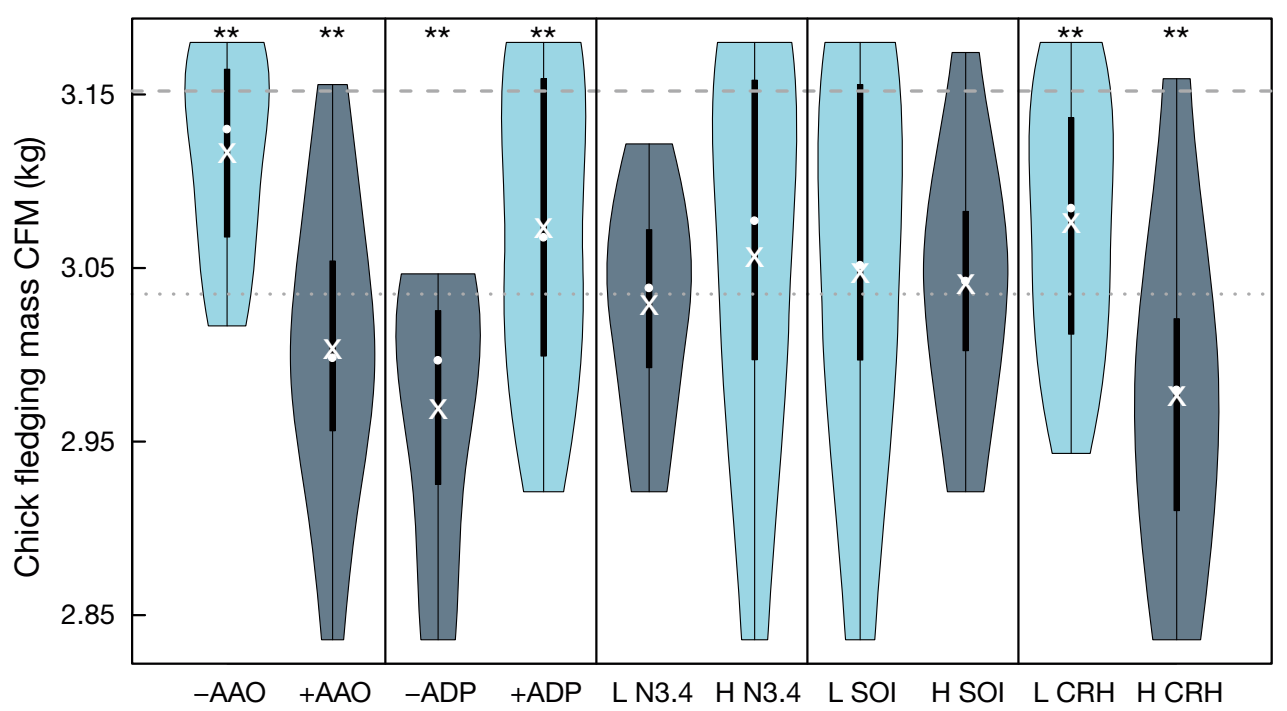

Fig. 4. Probability density of mean CFM between negative (-) and positive (+) or high (H) and low (L) Antarctic Oscillation (AAO) from 1987 to 2011, Antarctic Dipole (ADP) from 1987 to 2007, El Nino 3.4 (N3.4) from 1987 to 2011, Southern Oscillation Index (SOI) from 1987 to 2011, and chick-rearing habitat suitability (CRH) from 1987 to 2010. Blue and gray colors indicate higher and lower mean CFM, respectively. Significant differences between the means were computed using a $t$-test. Stars denote significant differences in the mean between - and + or $\mathrm{H}$ and $\mathrm{L}$ indices $\left({ }^{* *} \mathrm{p}<0.05 ;{ }^{*} \mathrm{p}<0.1\right)$. The dashed horizontal line represents surviving CFM; the dotted horizontal line represents non-surviving CFM. Thick black lines specify the interquartile range, thinner black lines are the upper and lower adjacent values, white points are the median, and X's are the mean

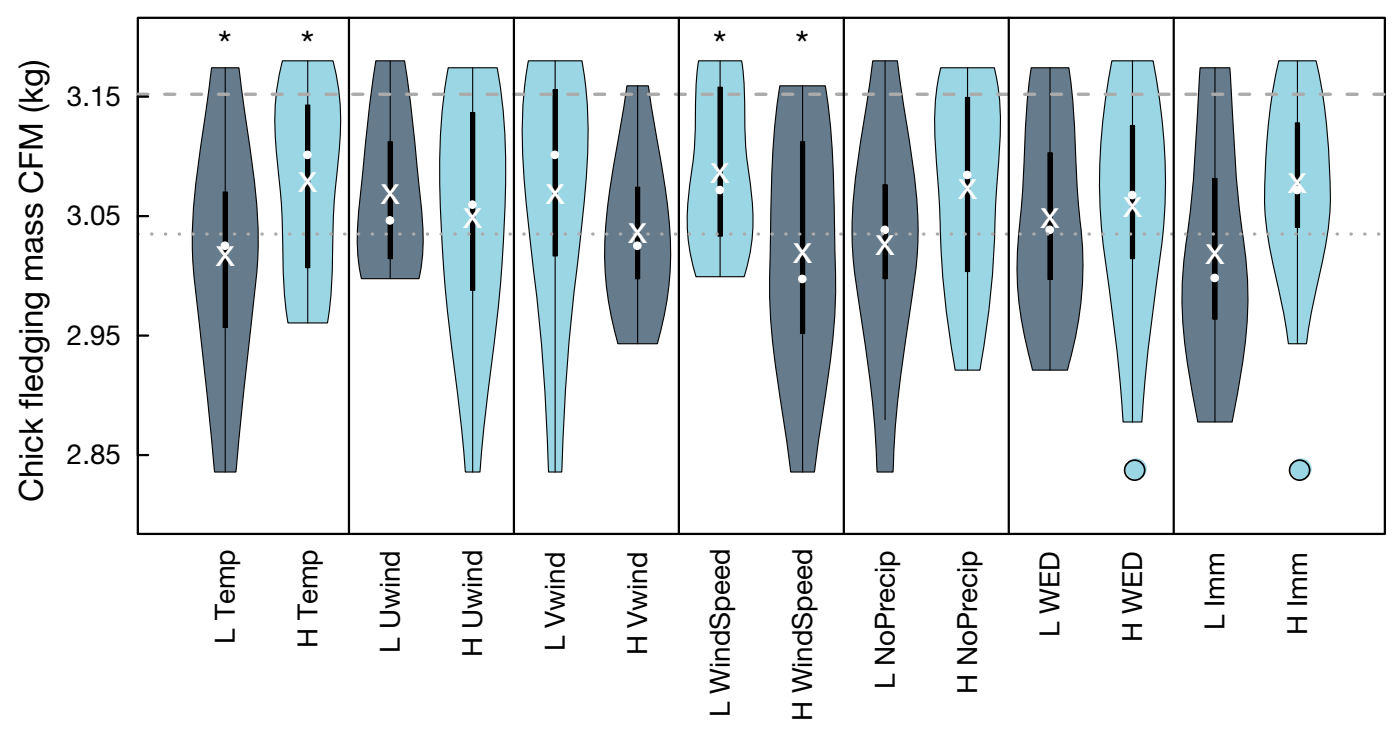

Fig. 5. Probability density of CFM between high (H) and low (L) air temperature (Temp), $u$ wind component (Uwind), $V$ wind component (Vwind), wind speed (WindSpeed), number of days with zero precipitation (NoPrecip), krill wet-mass energy density (WED), and the proportion of immature krill (Imm). Weather data spans 1989 to 2011, and krill data spans 1987 to 2011 during the chick-rearing period. Outlier points in the WED and immature krill boxes represent the year of lowest CFM in 2001, which was affected by anomalous weather events and excluded from significance testing. See Fig. 4 legend for more details

\section{Individual large- and local-scale predictors of CFM}

CFM was related to individual large-scale indices and local environmental factors (Figs. 4 \& 5). Mean CFM was significantly higher in years with a nega- tive AAO index, positive ADP, and low CRH suitability $(\mathrm{p}<0.05$; Fig. 4). There was no relationship between CFM and N3.4 or the SOI. In addition, CFM was marginally higher in years with warmer air temperature and lower wind speeds $(p<0.1$; Fig. 5). 


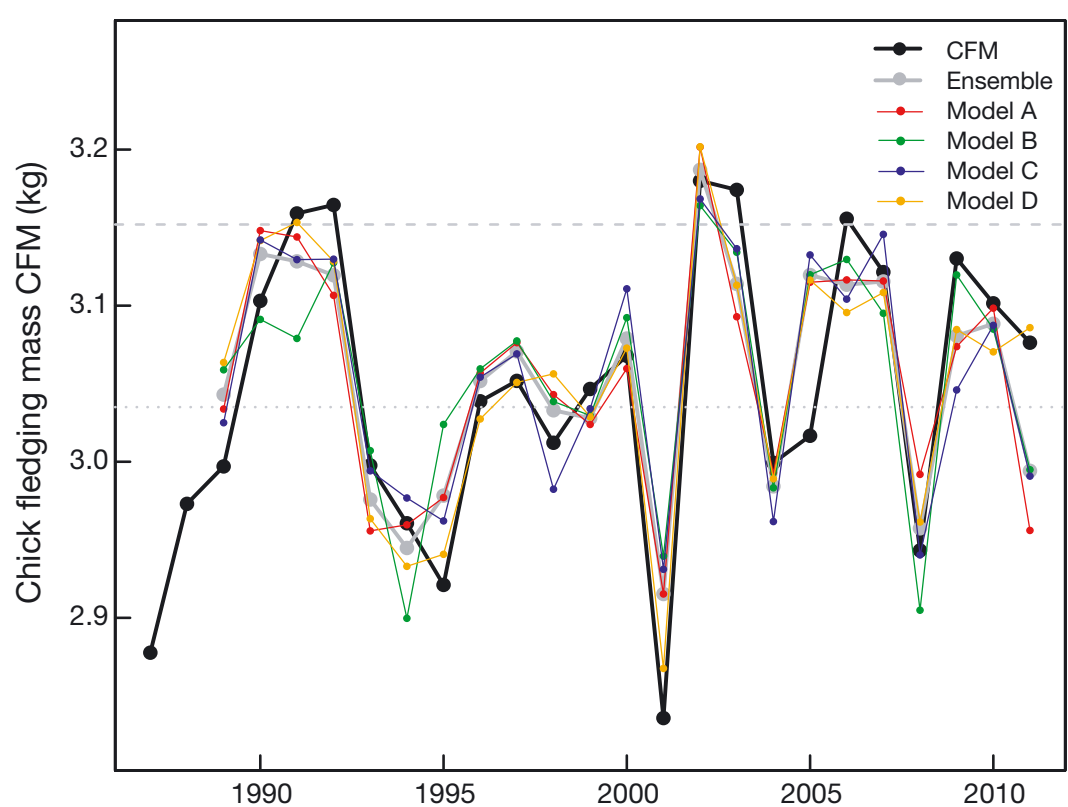

Fig. 6. Comparison of mean CFM and modeled CFM from Models A to D, which had substantial support $(\triangle \mathrm{AIC}<2)$. The ensemble is the mean of Models A to D, where the contribution of each model to the ensemble was weighted by the Akaike weights. The dashed horizontal line represents surviving CFM, while the dotted horizontal line represents non-surviving CFM
Models A-D, where the contribution of each model to the ensemble was weighted by the Akaike weights (Table 1). The ensemble was on average within $\sim 0.03 \mathrm{~kg}$ of measured CFM but ranged from 0.006 to $0.103 \mathrm{~kg}$. The ensemble had the greatest deviance from measured values in 2001, 2005, and 2011 by $0.079,0.103$, and $0.082 \mathrm{~kg}$, respectively. Conversely, Model D was able to more accurately estimate CFM in 2001 and 2011, but no model accurately estimated CFM in 2005.

There were 11 unique terms in Models A to D with varying importance to model performance. These included 7 linear predictor variables, 2 interactions between predictor variables, and 2 quadratic predictor variables (Fig. 7). The AAO and $u$ wind component were the only predictor variables used in all Models A to D. Additionally, AAO appeared in all reported models (Table 1 ). The $u$ wind component ranked the highest,
There was no significant relationship between CFM and the $u$ or $v$ wind component, the number of days with zero precipitation, WED, or the proportion of immature krill.

\section{Predictor variables of CFM from linear and polynomial regression}

Using stepwise regression, we related CFM to different environmental and prey predictor variables simultaneously (Table 1). The 4 best models (A to D) performed well and explained most of the variance $\left(\mathrm{R}^{2}=\sim 0.6\right.$ to 0.7$)$ using 5 to 8 predictor variables in quadratic and linear combinations. Model A explained the most variance using the fewest predictor variables and had the highest Akaike weight (35\%), which was roughly double that of Models B, C, and D. In comparison to Models B and C, Model D had a similar $\mathrm{AIC}_{\mathrm{C}}$ (within 0.5 units), relative likelihood $(\sim 50 \%)$, and Akaike weight $(\sim 15 \%)$ but explained $\sim 10 \%$ more variance using 2 to 3 more predictor variables.

We compared the measured CFM with estimated CFM from Models A-D from 1989 to 2011 (Fig. 6). The model estimates of CFM were generally in good agreement with the data. We created an ensemble of

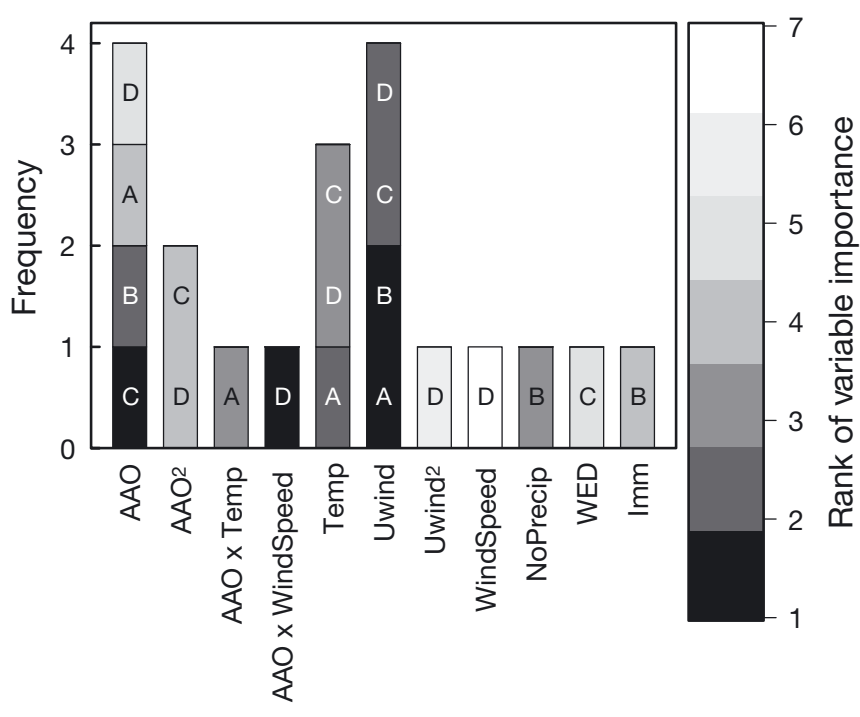

Fig. 7. The frequency that each predictor variable appeared in models that were substantially supported $(\triangle \mathrm{AIC}<2)$. Each variable was ranked in order of highest to lowest $t$-statistic for individual models, with 1 being the most predictive variable and 7 being the least. The letters (A to D) correspond to that respective model. The variables are Antarctic Oscillation (AAO), air temperature (Temp), $u$ wind component (Uwind), wind speed (WindSpeed), number of days with zero precipitation (NoPrecip), krill wet-mass energy density (WED), and the proportion of immature krill (Imm) 
being either the first- or second-most important variable in Models A to D. The AAO also ranked high in Models B and C but ranked fourth and fifth in Models A and D. However, in Models A and D, the interaction between air temperature and wind speed with

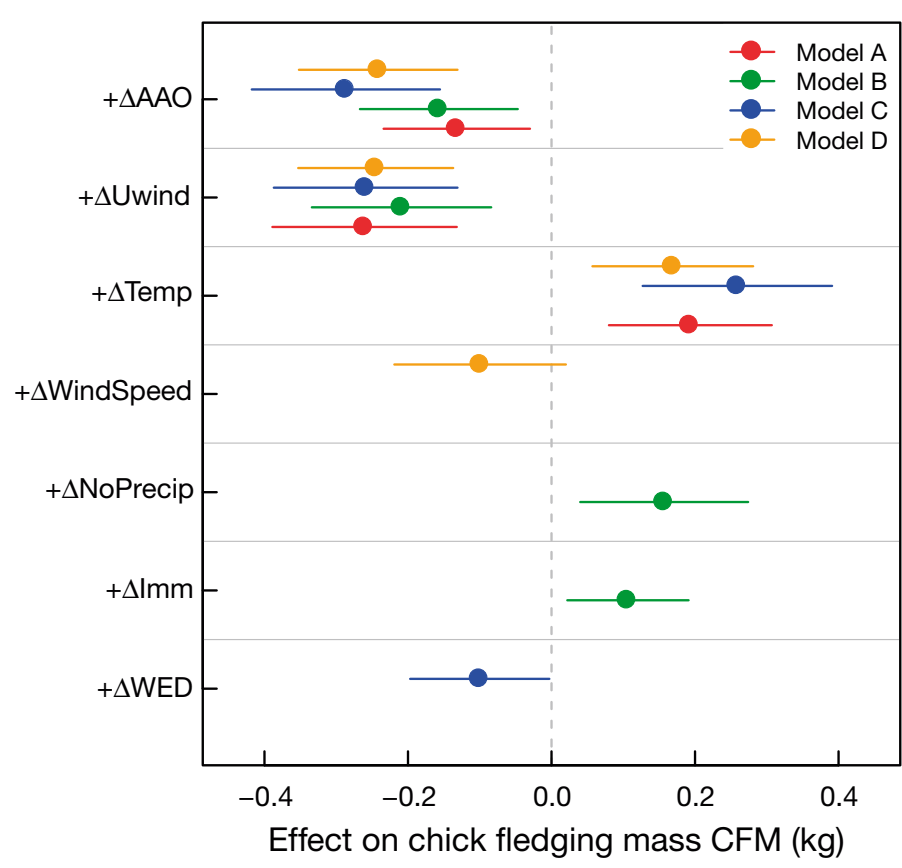

Fig. 8. Predicted effects on CFM when individual variables were increased in Models A to D. Each point represents the mean predicted effect on CFM, and the horizontal line is the $95 \%$ confidence interval from the prediction. The variables in the models are Antarctic Oscillation (AAO), air temperature (Temp), $u$ wind component (Uwind), wind speed (WindSpeed), number of days with zero precipitation (NoPrecip), krill wet-mass energy density (WED), and the proportion of immature krill (Imm)

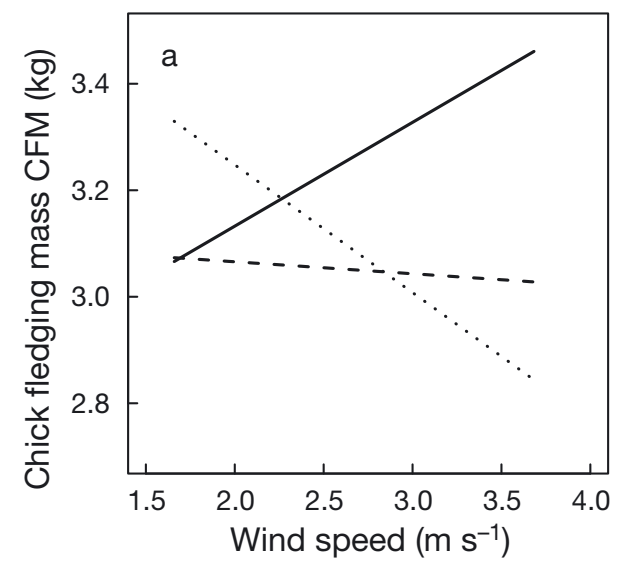

AAO ranked third and first. Air temperature ranked second in Model A and ranked third in Models C and D. The quadratic predictor variables were moderately important: $\mathrm{AAO}^{2}$ ranked fourth in Models $\mathrm{C}$ and $\mathrm{D}$, and $u$ wind ${ }^{2}$ ranked sixth in Model $\mathrm{D}$. The number of days with zero precipitation ranked third in Model B. Lastly, the 3 least important linear predictor variables to the models were wind speed, WED, and the proportion of immature krill, which all ranked last in their respective models.

The effects of each predictor variable on CFM were compared between models in a sensitivity test (Fig. 8). Increasing AAO, $u$ wind, air temperature, and precipitation individually had the greatest effect on CFM, confirming the parameter ranks in Fig. 7. A positive change in AAO and $u$ wind decreased CFM by $\sim 0.2 \mathrm{~kg}$, while a positive change in air temperature and the number of days with zero precipitation increased CFM by $\sim 0.2 \mathrm{~kg}$. Increased wind speed and WED decreased CFM by $\sim 0.1 \mathrm{~kg}$ and a higher proportion of immature krill increased CFM by $\sim 0.1 \mathrm{~kg}$. Parameters in Models A to D had a similar effect on CFM, confirming the consistency of different model predictions.

To understand the synergistic effects of wind speed and air temperature with AAO, we compared the sensitivity of CFM to wind speed and air temperature during a highly negative, low, and highly positive AAO index. During a negative AAO index, increased wind speed increased CFM, but during a positive $\mathrm{AAO}$, increased wind speed decreased CFM (Fig. 9a). When the AAO was low, wind speed had little to no effect on CFM. In addition, during a negative AAO, increased air temperature had little to no effect on CFM, but increased temperature in a positive and low AAO increased CFM (Fig. 9b).

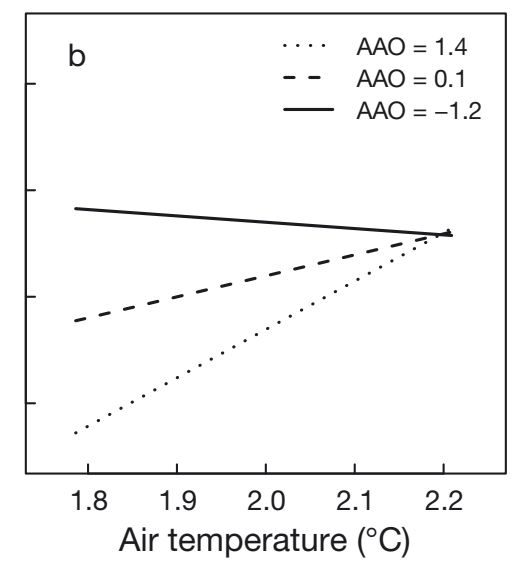

Fig. 9. Interactive effects on CFM between (a) wind speed and the Antarctic Oscillation (AAO) in Model A and (b) air temperature and AAO in Model D. Each line represents a positive, low, or negative AAO index 


\section{DISCUSSION}

High interannual variability is characteristic of the Antarctic ecosystem, but the relative contribution of large-scale and local processes in generating interannual variation in this ecosystem is largely unknown. In this study, we examined the relative importance of large-scale and local processes on the interannual variation in Adélie penguin CFM. Mean CFM at a colony represents the integrated investment of adults to the next generation and is the balance between seasonally integrated food resources and metabolic demand, both of which could be linked to large-scale and local processes in complex ways. To elucidate the major drivers of this variability, we tested environmental and prey factors acting on multiple spatial scales from 1987 to 2011. Our approach emphasizes the importance of uncorrelated predictor variables and quantifies the impact of interactions between these predictor variables on mean CFM. Our model results demonstrate that the largescale AAO, local westerly winds, and air temperature were the dominant predictor variables of CFM in our models (Fig. 7). These predictor variables caused a change in mean CFM by $\sim 0.2 \mathrm{~kg}$ (Fig. 8), which is greater than the difference between the mean masses of surviving and non-surviving chicks (Chapman et al. 2010, our Fig. 2). Our model results also show that the local mean wind speed, number of days with zero precipitation, dietary proportion of immature krill, and WED were less important predictor variables of mean CFM (Fig. 8). This highlights the importance of large-scale and local weather conditions at a penguin colony, relative to krill resources (Fig. 3). In the remainder of the discussion, we will provide the major interpretations of our model results as they relate to large-scale climate, local weather, their potential interactions, and food resource quality.

\section{Large-scale climate predictors of CFM}

The implicit assumption of large-scale climate correlates to local biological measurements is that the climate index is associated with multiple localscale oceanographic conditions or weather phenomena that directly affect a biological system. We examined 5 different climate indices that have been hypothesized to influence ecosystem variability along the WAP (Fig. 4). Of the 5 indices we examined, 3 (AAO, ADP, and $\mathrm{CRH}$ ) have significant relationships with CFM. The AAO has been positively correlated to a western wind anomaly, air temperatures, precipitation, and moisture along the WAP (Oshima \& Yamazaki 2004, van den Broeke \& van Lipzig 2004) and may represent a synergy between many local climate forces that could subsequently affect penguin chicks. Multiple studies have suggested that the austral winter ADP (once referred to as the Antarctic Circumpolar Wave) impacts Adélie penguins (Clarke et al. 2002, Fraser \& Hofmann 2003, Ainley et al. 2005) through the influence of winter sea ice on krill reproductive output and survival (Quetin \& Ross 2003) and, thus, on food availability for penguins. In this study, we provide the first preliminary results indicating that CFM covaries with the austral summer ADP index (Fig. 4); however, the mechanisms linking austral summer ADP and CFM are unknown. CRH suitability is an index that incorporates sea surface temperature, sea ice, and bathymetry that is indicative of Adélie penguin chick-rearing habitats (Cimino et al. 2013). CRH suitability indices were originally developed to predict whether or not Adélie penguin colonies were growing or shrinking. Surprisingly, low CRH suitability was significantly related to high CFM (Fig. 4). During years of low CRH suitability, the air temperature was warmer (Fig. S1 in Supplement 2), which suggests that although a warming environment has a negative effect on Adélie populations (Cimino et al. 2013), the warmer air temperature may decrease thermoregulatory costs for chicks.

In our best-performing regression models (Table 1), the AAO was a leading and only large-scale climate index predictor for CFM. All other climate indices except ADP were rejected prior to modeling because they were highly collinear with other environmental predictor variables and likely detected similar climate signals (Fig. S1). ADP was rejected because the record was incomplete (available only through 2007). Although the AAO has been implicated in driving local weather patterns along the WAP, we found only moderate correlations between AAO and the mean wind speed $(\rho=0.41, p=0.05$ ) and days with zero precipitation $(\rho=-0.37, p=0.08)$ but found no correlation between westerly winds $(+u)$ or air temperature (Fig. S1). The AAO is linked by remote forcing of atmospheric teleconnections to the local environment, which may not be manifested in mean local weather conditions at Palmer Station. This suggests that the significance of the AAO as a predictor of CFM is not due to a correlation with any one weather signal but represents an integrated but unknown mixture of climate forces as they relate to interannual variability in CFM. For 
instance, austral winters of high sea ice extent and spring physical processes (low wind and high salinity-driven density gradients in the upper water column), modulated by negative July and spring (September to November) AAO events, promote high phytoplankton biomass at Palmer Station (Saba et al. 2014). Summers with high chl a anomalies were in turn significantly correlated with the start of a new krill cohort, which was evident in penguin diets the following summer. This demonstrates a tight coupling within the food web (Saba et al. 2014) and the varying impact of climate and weather forces on different trophic levels.

\section{Local weather predictors of CFM}

We tested the effects of multiple local weather conditions on CFM using different metrics for air temperature, wind, and precipitation (Fig. 4, Table S1 in Supplement 1). Individually, these parameters did not have a strong relationship with CFM (Fig. 5). However, results from our stepwise regressions (Table 1) indicate that the $u$ wind component and air temperature were major predictor variables of CFM, causing $\sim 0.2 \mathrm{~kg}$ change, while wind speed and days with zero precipitation were minor predictor variables, causing $\sim 0.1 \mathrm{~kg}$ change in CFM (Figs. $7 \& 8$ ). The negative effect of low air temperature alone does not provide a mechanistic link to CFM because chicks can withstand a wide range of temperatures (Chappell et al. 1989), but we will discuss this negative effect further in the next section in relation to the statistical interaction with other predictor variables. Although precipitation was not a key predictor variable in our models, it can cause the plumage of chicks to become damp or wet and is generally a major factor causing egg and chick mortality and slow growth due to hypothermia (Konarzewski \& Taylor 1989, Thyen \& Becker 2006). For example, Boersma \& Rebstock (2014) found more chicks died when rainfall was high and air temperature was low. Wetness decreases the insulating properties of feathers, and this disruption likely increases heat loss (McCafferty et al. 1997, Wilson et al. 2004). Therefore, more days with no precipitation have a positive effect on CFM likely due to lower thermoregulatory costs.

Local winds were a strong predictor of CFM in our models. Onshore westerly winds and to a lesser extent wind speeds could indirectly affect a parent's foraging domain and directly affect a chick's terrestrial habitat. In the Falkland Islands, strong westerly winds were hypothesized to aggregate prey and were correlated to Rockhopper penguin mass gain (Dehnhard et al. 2013). Prey distributions may be affected by regional ocean circulation, fronts, eddies, current velocities, and water mass distributions (Trivelpiece \& Fraser 1996), which can be affected by strong winds. Over small spatial $(10 \mathrm{~s}$ of $\mathrm{km})$ and temporal (days) scales, a near gale can alter nearshore hydrography in the upper $100 \mathrm{~m}$ of the water column, decrease krill biomass, and change the foraging distribution of krill predators (Warren et al. 2009). Alternatively, wind is hypothesized to have adverse effects on CFM and seabird survival (Finney et al. 1999, Chapman et al. 2011) in locations with little shelter from the prevailing wind or onshore wind component (Harris \& Wanless 1996, Frederiksen et al. 2008). Winds can influence where snowfall will accumulate or which locations will receive the most wind scour (Fraser et al. 2013).

\section{Climate and weather interaction predictor variables of CFM}

Interactions between our predictor variables provide insight into how CFM is synergistically affected by the large- and local-scale environment (Fig. 9). During summers of a positive AAO index with high wind speeds (Fig. 9a) and low air temperatures (Fig. 9b), CFM was lower. As previously discussed, the AAO is likely a synergy between many local weather factors at Palmer Station. However, the AAO is positively correlated to the number of days with precipitation and is likely an indicator of humidity. Our interpretation of these interactions is that chicks are more likely to become wet during a positive AAO and incur higher thermoregulative costs during wet, cold, and windy years (Lustick \& Adams 1977). When the AAO is negative, or near zero, the effect of air temperature on CFM is eliminated or reduced. Additionally, when the AAO is negative, wind speed is positively related to CFM. The reasons for this particular relationship are unknown. This interaction relationship points to the importance of local wind speed on either food resources or nest site conditions. A previous study of Adélie penguins in East Antarctica also linked interannual variation in breeding phenology to the AAO, air temperature, wind speed and direction (Emmerson et al. 2011). This suggests our predictor variables are not unique to Adélie chicks at Humble Island and can impact many parts of the Adélie life cycle. 


\section{Food resource predictors of CFM}

We examined the impact of interannual variability in krill WED and demography on CFM because krill is the main food source for Adélie penguins on Humble Island during our study period. In our regression models (Table 1), we found the proportion of immature krill and WED had a minor contribution to model predictions, causing a change in CFM by $\sim 0.1 \mathrm{~kg}$ (Figs. 7 \& 8). It was counterintuitive to find that increased WED corresponded to lower CFM (Fig. 8) because high-energy prey should increase chick growth (Drent \& Daan 1980, Litzow et al. 2002). However, finding higher-energy prey could pose a greater time cost to the parent and reduce the frequency or amount of food delivered to the chick. The negative relationship between WED and CFM suggests that a diet of high energy content does not necessarily produce chicks with a higher mass. Therefore, it may be plausible for a chick to attain the same amount of energy from a diet of gravid females and immature krill. Other studies suggest krill biomass (Trivelpiece et al. 2011) or meal mass (Clarke et al. 2002 ) is the dominant driver of demographic changes or chick survival in Adélie penguins.

Determining the dietary proportion of each sex and maturity stage of krill from shifting size class frequency distributions (Ducklow et al. 2013) required fewer assumptions compared to WED (Eqs. S1 \& S2 in Supplement 3). A higher proportion of immature krill had a positive effect on CFM (Fig. 8). A higher proportion of small krill may be indicative of a higher level of krill recruitment (Lynnes et al. 2004) and increased encounter rates for penguins, making foraging trips shorter and allowing chicks to be provisioned at more frequent intervals (Fraser \& Hofmann 2003). Hinke et al. (2007) showed that the recruitment of Adélie penguins was positively related to small krill, which could suggest that small krill influences CFM. However, Hinke et al. (2007) did not detect a relationship between small krill and CFM because they looked at mean krill size in Adélie diets, which they found was not correlated to CFM. Lynnes et al. (2004) also found Adélie penguins exhibited stronger recruitment in years with a higher proportion of smaller krill. Alternatively, a diet of immature krill may be easier for chicks to digest and result in high assimilation efficiencies. For example, penguins digest fish quicker than squid (Wilson et al. 1985, van Heezik \& Seddon 1989) and digest smaller otoliths faster than larger otoliths (van Heezik \& Seddon 1989). Therefore, the small carapace of juvenile krill may be digested more rapidly than the thicker and more developed carapace of mature krill. Recently at Palmer Station, other krill-consuming penguin species have established breeding colonies with growing populations and similar foraging distributions to Adélie penguins, which suggests krill are not a limiting resource and should not be a dominant predictor variable of CFM. Although krill energy content and demography are not main drivers in our models, this should not underscore the importance of krill in this ecosystem. In general, regional declines in krill biomass and variability in recruitment (Siegel \& Loeb 1995, Loeb et al. 1997) have indications for negative density dependence and juvenile mortality even if chicks reach a surviving mass.

\section{Potential sources of unexplained model variance and non-significant predictor variables}

The accuracy of our CFM models was generally supported by the data (Fig. 6), but 30 to $40 \%$ of the variability in CFM remains unexplained (Table 1), which shows our approach did not account for all processes or interactions involved in parental care or chick growth. We did not directly account for all factors affecting a parent's ability to forage efficiently due to inter/intraspecific competition (Ducklow et al. 2007, Siniff et al. 2008), foraging duration/behavior (Watanuki et al. 2002, Takahashi et al. 2003), barriers (such as thick ice cover), food availability, parent age/experience (Ainley \& Schlatter 1972, Ainley 2002), and parent body condition (Tveraa et al. 1998, Ballard et al. 2010). Notably, we found few indications of heat stress during the chick-rearing period. Heat stress is known to cause behavioral changes in penguins around Palmer Station (W. R. Fraser pers. obs.), which suggests the effects of heat operate at finer temporal scales than our daily mean weather observations can detect. We also tested for the effect of the tidal regime as a predictor variable of CFM. It has been suggested that tides are active aggregators of krill in the region (Bernard \& Steinberg 2013, Oliver et al. 2013), but the seasonal fraction of diurnal tides were a non-significant predictor of CFM. However, our treatment of the tides as seasonal fractions may be overly simplistic.

Within our study period, the documented effects of atmospheric events on Adélie penguins point to overlooked predictor variables in our models. In 2001, an anomalous blocking-high pattern coincided with a positive summer AAO, the lowest mean CFM in our time series, low reproductive success, the largest between-season population decline, and deferred 
breeding by many birds at Palmer Station (Massom et al. 2006). This was triggered by a strong and persistent north-northwesterly flow of mild and moist air across the WAP, extreme ice compaction, high snowfall, thick snow cover, and subsequent high temperatures that caused snowmelt to flood nests and drown eggs and small chicks. A similar event occurred in 2005, coincident with a near neutral AAO (Massom et al. 2008). Although atmospheric anomalies on this scale are extremely rare (Turner et al. 2002), it is unknown if blocking-high episodes will become more prevalent in future climate scenarios.

\section{CONCLUSIONS}

Understanding the interannual variability in Adélie mean CFM using large and local-scale predictor variables is fundamental to gaining a more robust understanding of Adélie penguins' response to environmental variability in Antarctica. We expected krill predictor variables to play a larger role in predicting CFM; however, large-scale climate and local weather were more important. It is unclear how general our results are with respect to the rest of the Antarctic continent. Along the WAP, a positive austral summer AAO produces warm, windy, and humid conditions, while cold, calm, and dry conditions occur in East Antarctica. Therefore, opposing effects of the AAO around the continent may explain the opposing patterns in Adélie demography and population trends (Ainley et al. 2005, Emmerson et al. 2011, Hindell et al. 2012). Our results suggest that climate and weather are dominant drivers of mean CFM; however, there is still a significant amount of variance in CFM that we could not explain. We suggest that a more detailed analysis of overwintering conditions and parental foraging behavior during the chick-rearing period are important for understanding the variation in mean CFM.

Acknowledgements. The research described in this paper was supported by long-term funding from the National Marine Fisheries Service and National Science Foundation grants 8918324, 9011927, 9103429, 9320115, 9505596, 9632763，9910095，0130525，0217282，0224727，0523261， 0741351, and 0823101 and NASA grant NNX09AK24G. We thank Tony Amos for tide data, Xiaojun Yuan for the ADP index, and Sharon Stammerjohn for sea ice data.

\section{LITERATURE CITED}

Ainley DG (2002) The Adélie penguin: bellwether of climate change. Columbia University Press, New York, NY
Ainley DG, Schlatter RP (1972) Chick raising ability in Adélie penguins. Auk 89:559-566

Ainley D, Clarke E, Arrigo K, Fraser W, Kato A, Barton K, Wilson P (2005) Decadal-scale changes in the climate and biota of the Pacific sector of the Southern Ocean, 1950s to the 1990s. Antarct Sci 17:171-182

Allison PD (1999) Multiple regression: a primer. Pine Forge Press, Thousand Oaks, CA

Amos A (1993) RACER: the tides at Palmer Station. Antarct J US 28:162-164

Atkinson A, Siegel V, Pakhomov E, Rothery P (2004) Longterm decline in krill stock and increase in salps within the Southern Ocean. Nature 432:100-103

Ballard G, Toniolo V, Ainley DG, Parkinson CL, Arrigo KR, Trathan PN (2010) Responding to climate change: Adélie penguins confront astronomical and ocean boundaries. Ecology 91:2056-2069

> Baylis AMM, Zuur AF, Brickle P, Pistorius PA (2012) Climate as a driver of population variability in breeding Gentoo penguins at the Falkland Islands. Ibis 154:30-41

Bernard KS, Steinberg DK (2013) Krill biomass and aggregation structure in relation to tidal cycle in a penguin foraging region off the Western Antarctic Peninsula. ICES J Mar Sci 70:834-849

> Boersma PD, Rebstock GA (2014) Climate change increases reproductive failure in Magellanic penguins. PLoS ONE 9:e85602

> Bucher TL, Chappell MA, Morgan KR (1990) The ontogeny of oxygen consumption and ventilation in the Adelie penguin, Pygoscelis adeliae. Respir Physiol 82:369-388

Burnham KP, Anderson DR (2002) Model selection and multi-model inference: a practical information-theoretic approach. Springer, New York, NY

Carleton AM (2003) Atmospheric teleconnections involving the Southern Ocean. J Geophys Res 108:1-15

Chapman EW, Hofmann EE, Patterson DL, Fraser WR (2010) The effects of variability in Antarctic krill (Euphausia superba) spawning behavior and sex/maturity stage distribution on Adélie penguin (Pygoscelis adeliae) chick growth: a modeling study. Deep-Sea Res II 57:543-558

Chapman EW, Hofmann EE, Patterson DL, Ribic CA, Fraser WR (2011) Marine and terrestrial factors affecting Adelie penguin Pygoscelis adeliae chick growth and recruitment off the western Antarctic Peninsula. Mar Ecol Prog Ser 436:273-289

Chappell MA, Morgan KR, Souza SL, Bucher TL (1989) Convection and thermoregulation in two Antarctic seabirds. J Comp Physiol B 159:313-322

Chappell MA, Morgan KR, Bucher TL (1990) Weather, microclimate, and energy costs of thermoregulation for breeding Adelie penguins. Oecologia 83:420-426

Cimino MA, Fraser WR, Irwin AJ, Oliver MJ (2013) Satellite data identify decadal trends in the quality of Pygoscelis penguin chick-rearing habitat. Glob Chang Biol 19: 136-148

> Clarke J, Kerry K, Irvine L, Phillips B (2002) Chick provisioning and breeding success of Adélie penguins at Bechervaise Island over eight successive seasons. Polar Biol 25: 21-30

> Davis LS (1982) Creching behaviour of Adelie penguin chicks. NZ J Zool 9:279-285

> Davis RW, Croxall JP, O'Connell MJ (1989) The reproductive energetics of gentoo (Pygoscelis papua) and macaroni (Eudyptes chrysolophus) penguins at South Georgia. J Anim Ecol 58:59-74 
Dehnhard N, Ludynia K, Poisbleau M, Demongin L, Quillfeldt P (2013) Good days, bad days: wind as a driver of foraging success in a flightless seabird, the southern Rockhopper Penguin. PLoS ONE 8:e79487

Demongin L, Poisbleau M, Strange IJ, Quillfeldt P (2010) Effects of severe rains on the mortality of southern rockhopper penguin (Eudyptes chrysocome) chicks and its impact on breeding success. Ornitol Neotrop 21:439-443

Drent RH, Daan S (1980) The prudent parent: energetic adjustments in avian breeding. Ardea 68:225-252

Ducklow HW, Baker K, Martinson DG, Quetin LB and others (2007) Marine pelagic ecosystems: the west Antarctic Peninsula. Philos Trans R Soc Lond B 362:67-94

> Ducklow H, Fraser W, Meredith M, Stammerjohn S and others (2013) West Antarctic Peninsula: an ice-dependent coastal marine ecosystem in transition. Oceanography (Wash DC) 26:190-203

> Emmerson L, Pike R, Southwell C (2011) Reproductive consequences of environment-driven variation in Adélie penguin breeding phenology. Mar Ecol Prog Ser 440: 203-216

> Finney S, Wanless S, Harris M (1999) The effect of weather conditions on the feeding behaviour of a diving bird, the common guillemot Uria aalge. J Avian Biol 30:23-30

> Forcada J, Trathan PN (2009) Penguin responses to climate change in the Southern Ocean. Glob Change Biol 15: 1618-1630

> Forcada J, Trathan P, Reid K, Murphy E, Croxall J (2006) Contrasting population changes in sympatric penguin species in association with climate warming. Glob Change Biol 12:411-423

> Fraser WR, Hofmann EE (2003) A predator's perspective on causal links between climate change, physical forcing and ecosystem response. Mar Ecol Prog Ser 265:1-15

Fraser WR, Patterson-Fraser DLR, Ribic CA, Schofield O, Ducklow H (2013) A nonmarine source of variability in Adélie penguin demography. Oceanography (Wash DC) 26:207-209

Frederiksen M, Daunt F, Harris MP, Wanless S (2008) The demographic impact of extreme events: stochastic weather drives survival and population dynamics in a long-lived seabird. J Anim Ecol 77:1020-1029

> Graf RF, Bollmann K, Suter W, Bugmann H (2005) The importance of spatial scale in habitat models: capercaillie in the Swiss Alps. Landscape Ecol 20:703-717

> Harris MP, Wanless S (1996) Differential responses of Guillemot and Shag to a late winter wreck. Bird Study 43:220-230

Hindell MA, Bradshaw CJA, Brook BW, Fordham DA, Kerry K, Hull C, Mcmahon CR (2012) Long-term breeding phenology shift in royal penguins. Ecol Evol 2:1563-1571

Hinke JT, Salwicka K, Trivelpiece SG, Watters GM, Trivelpiece WZ (2007) Divergent responses of Pygoscelis penguins reveal a common environmental driver. Oecologia 153:845-855

Janes DN, Chappell MA (1995) The effect of ration size and body size on specific dynamic action in Adélie penguin chicks, Pygoscelis adeliae. Physiol Zool 68:1029-1044

> Jarvis MJF (1974) The ecological significance of clutch size in the South African Gannet (Sula capensis). J Anim Ecol 43:1-18

> Jenouvrier S, Weimerskirch H, Barbraud C, Park YH, Cazelles B (2005) Evidence of a shift in the cyclicity of Antarctic seabird dynamics linked to climate. Proc Biol Sci 272:887-895
Konarzewski M, Taylor JRE (1989) The influence of weather conditions on growth of Little Auk Alle alle chicks. Ornis Scand 20:112-116

Kuhn M, Johnson K (2013) Applied predictive modeling. Springer, New York, NY

Kwok R, Comiso J (2002) Southern Ocean climate and sea ice anomalies associated with the Southern Oscillation. J Clim 15:487-501

> Lawless RM, Buttemer WA, Astheimer LB, Kerry KR (2001) The influence of thermoregulatory demand on contact creching behaviour in Adélie Penguin chicks. J Therm Biol 26:555-562

> Le Bohec C, Durant JM, Gauthier-Clerc M, Stenseth NC and others (2008) King penguin population threatened by Southern Ocean warming. Proc Natl Acad Sci USA 105: 2493-2497

> Litzow M, Piatt J, Prichard A, Roby D (2002) Response of pigeon guillemots to variable abundance of high-lipid and low-lipid prey. Oecologia 132:286-295

> Loeb V, Siegel V, Holm-Hansen O, Hewitt R, Fraser W, Trivelpiece W, Trivelpiece S (1997) Effects of sea-ice extent and krill or salp dominance on the Antarctic food web. Nature 387:897-900

> Lustick S, Adams J (1977) Seasonal variation in the effects of wetting on the energetics and survival of starlings (Sturnus vulgaris). Comp Biochem Physiol A 56:173-177

> Lynnes A, Reid K, Croxall J (2004) Diet and reproductive success of Adélie and chinstrap penguins: linking response of predators to prey population dynamics. Polar Biol 27:544-554

> Massom RA, Stammerjohn SE (2010) Antarctic sea ice change and variability - physical and ecological implications. Polar Sci 4:149-186

- Massom RA, Stammerjohn SE, Smith RC, Pook MJ and others (2006) Extreme anomalous atmospheric circulation in the West Antarctic Peninsula region in austral spring and summer 2001/02, and its profound impact on sea ice and biota. J Clim 19:3544-3571

Massom RA, Stammerjohn SE, Lefebvre W, Harangozo SA and others (2008) West Antarctic Peninsula sea ice in 2005: extreme ice compaction and ice edge retreat due to strong anomaly with respect to climate. J Geophys Res 113:C02S20

McCafferty DJ, Moncrieff JB, Taylor IR (1997) The effect of wind speed and wetting on thermal resistance of the barn owl (Tyto alba). II: Coat resistance. J Therm Biol 22: 265-273

Meredith MP, King JC (2005) Rapid climate change in the ocean west of the Antarctic Peninsula during the second half of the 20th century. Geophys Res Lett 32:1-5

> Moline MA, Claustre H, Frazer TK, Schofield O, Vernet M (2004) Alteration of the food web along the Antarctic Peninsula in response to a regional warming trend. Glob Change Biol 10:1973-1980

> Montes-Hugo M, Doney SC, Ducklow HW, Fraser W, Martinson D, Stammerjohn SE, Schofield O (2009) Recent changes in phytoplankton communities associated with rapid regional climate change along the western Antarctic Peninsula. Science 323:1470-1473

> Morrison KW, Hipfner JM, Gjerdrum C, Green DJ (2009) Wing length and mass at fledgling predict local survival and age at first return in tufted puffins. Condor 111: 433-441

Muller-Schwarze D (1984) The behavior of penguins: adapted to ice and tropics. State University of New York 
Press, Albany, NY

Murrish DE (1983) Acid-base balance in penguin chicks exposed to thermal stress. Physiol Zool 56:335-339

Naef-Daenzer B, Widmer F, Nuber M (2001) Differential post-fledging survival of great and coal tits in relation to their condition and fledging date. J Anim Ecol 70 : 730-738

Nagy KA, Obst BS (1992) Food and energy requirements of Adélie penguins (Pygoscelis adeliae) on the Antarctic Peninsula. Physiol Zool 65:1271-1284

O'Brien RM (2007) A caution regarding rules of thumb for variance inflation factors. Qual Quant 41:673-690

- Oliver MJ, Irwin A, Moline MA, Fraser W, Patterson D, Schofield O, Kohut J (2013) Adélie penguin foraging location predicted by tidal regime switching. PLoS ONE 8:e55163

Olmastroni S, Pezzo F, Volpi V, Forcadi S (2004) Effects of weather and sea ice on the reproductive performance of the Adélie penguin at Edmonson point, Ross Sea. CCAMLR Science 11:99-109

Oshima K, Yamazaki K (2004) Seasonal variation of moisture transport in polar regions and the relation with annular modes. Polar Meteorol Glaciol 18:30-53

Patterson DL, Easter-Pilcher A, Fraser WR (2003) The effects of human activity and environmental variability on longterm changes in Adelie penguin populations at Palmer Station, Antarctica. In: Huiskes AHL, Gieskes WWC, Rozema J, Schorno RML, van der Vies SM, Wolff WJ (ed) Antarctic biology in a global context. Backhuys, Leiden, p 301-307

Quetin LB, Ross RM (2001) Environmental variability and its impact on the reproductive cycle of Antarctic krill. Integr Comp Biol 41:74-89

Quetin L, Ross R (2003) Episodic recruitment in Antarctic krill Euphausia superba in the Palmer LTER study region. Mar Ecol Prog Ser 259:185-200

Saba GK, Fraser WR, Saba VS, Iannuzzi RA and others (2014) Winter and spring controls on the summer food web of the coastal West Antarctic Peninsula. Nat Commun 5:4318

Salihoglu B, Fraser W, Hofmann E (2001) Factors affecting fledging weight of Adelie penguin (Pygoscelis adeliae) chicks: a modeling study. Polar Biol 24:328-337

Saraux C, Viblanc VA, Hanuise N, Le Maho Y, Le Bohec C (2011) Effects of individual pre-fledging traits and environmental conditions on return patterns in juvenile king penguins. PLoS ONE 6:e20407

Schreiber EA (2002) Climate and weather effects on seabirds. In: Schreiber EA, Burger J (eds) Biology of marine birds. CRC Press, Boca Raton, FL, p 179-215

> Siegel V, Loeb V (1995) Recruitment of Antarctic krill Euphausia superba and possible causes for its variability. Mar Ecol Prog Ser 123:45-56

Siniff DB, Garrott RA, Rotella JJ, Fraser WR, Ainley DG (2008) Opinion: projecting the effects of environmental change on Antarctic seals. Antarct Sci 20:425-435

Smith RC, Ainley D, Baker K, Domack E and others (1999) Marine ecosystem sensitivity to climate change. Bioscience 49:393-404

Stammerjohn SE, Martinson DG, Smith RC, Yuan X, Rind D (2008) Trends in Antarctic annual sea ice retreat and advance and their relation to El Nino Southern Oscillation and Southern Annular Mode variability. J Geophys Res 113:C03S90, doi: 10.1029/2007JC004269

Stammerjohn S, Massom R, Rind D, Martinson D (2012)
Regions of rapid sea ice change: an inter-hemispheric seasonal comparison. Geophys Res Lett 39:L06501, doi: 10.1029/2012GL050874

Suppiah R, Hennessy K, Whetton P, Mcinnes K and others (2007) Australian climate change projections derived from simulations performed for the IPCC 4th Assessment Report. Aust Meteorol Mag 56:131-152

Takahashi A, Watanuki Y, Sato K, Kato A, Arai N, Nishikawa J, Naito Y (2003) Parental foraging effort and offspring growth in Adélie penguins: Does working hard improve reproductive success? Funct Ecol 17:590-597

> Thyen S, Becker P (2006) Effects of individual life-history traits and weather on reproductive output of Blackheaded gulls Larus ridibundus breeding in the Wadden Sea, 1991-1997. Bird Study 53:132-141

Trathan PN, Murphy EJ, Forcada J, Croxall JP, Reid K, Thorpe SE (2006) Physical forcing in the southwest Atlantic: ecosystem control. Cambridge University Press, Cambridge

Trivelpiece WZ, Fraser WR (1996) The breeding biology and distribution of Adélie penguins: adaptations to environmental variability. In: Hofmann EE, Ross RM, Quetin LB (eds) Foundations for ecological research west of the Antarctic Peninsula. American Geophysical Union, Washington, DC, p 273-285

Trivelpiece WZ, Hinke JT, Miller AK, Reiss CS, Trivelpiece SG, Watters GM (2011) Variability in krill biomass links harvesting and climate warming to penguin population changes in Antarctica. Proc Natl Acad Sci USA 108: 7625-7628

Turner J, Harangozo SA, Marshall GJ, King JC, Colwell SR (2002) Anomalous atmospheric circulation over the Weddell Sea, Antarctica during the austral summer of 2001/02 resulting in extreme sea ice conditions. Geophys Res Lett 29:2160, doi: 10.1029/2002GL015565

Tveraa T, Sether BE, Aanes R, Erikstad KE (1998) Regulation of food provisioning in the Antarctic petrel; the importance of parental body condition and chick body mass. J Anim Ecol 67:699-704

> van den Broeke MR, van Lipzig NPM (2004) Changes in Antarctic temperature, wind and precipitation in response to the Antarctic Oscillation. Ann Glaciol 39: 119-126

van Heezik Y, Seddon P (1989) Stomach sampling in the yellow-eyed penguin: erosion of otoliths and squid beaks. J Field Ornithol 451-458

> Vaughan DG, Marshall GJ, Connolley WM, Parkinson C and others (2003) Recent rapid regional climate warming on the Antarctic Peninsula. Clim Change 60:243-274

> Warren JD, Santora JA, Demer DA (2009) Submesoscale distribution of Antarctic krill and its avian and pinniped predators before and after a near gale. Mar Biol 156: 479-491

Watanuki Y, Kato A, Sato K, Niizuma Y, Bost CA, Le Maho Y, Naito Y (2002) Parental mass change and food provisioning in Adélie penguins rearing chicks in colonies with contrasting sea-ice conditions. Polar Biol 25: 672-681

- Wilson GR, Cooper SJ, Gessaman JA (2004) The effects of temperature and artificial rain on the metabolism of American kestrels (Falco sparverius). Comp Biochem Physiol A Mol Integr Physiol 139:389-394

Wilson PR, Ainley DG, Nur N, Jacobs SS, Barton KJ, Ballard G, Comiso JC (2001) Adélie penguin population change in the Pacific sector of Antarctica: relation to sea-ice 
extent and the Antarctic Circumpolar Current. Mar Ecol Prog Ser 213:301-309

Wilson R (1984) An improved stomach pump for penguins and other seabirds. J Field Ornithol 55:109-112

Wilson RP, Lacock GD, Wilson MP, Mollagee F (1985) Differential digestion of fish and squid in jackass penguins

Editorial responsibility: Rory Wilson,

Swansea, UK
Spheniscus demersus. Ornis Scand 16:77-79

Yuan X (2004) ENSO-related impacts on Antarctic sea ice: a synthesis of phenomenon and mechanisms. Antarct Sci 16:415-425

Yuan X, Martinson DG (2001) The Antarctic dipole and its predictability. Geophys Res Lett 28:3609-3612

Submitted: January 16, 2014; Accepted: June 25, 2014

Proofs received from author(s): September 23, 2014 